\title{
Vitamin B6 reduces oxidative stress in lungs and liver in experimental sepsis
}

\author{
AMANDA D. GIUSTINA, LUCINÉIA G. DANIELSKI, MICHELE M. NOVOCHADLO, MARIANA \\ P.S. GOLDIM, LARISSA JOAQUIM, KIUANNE L.L. METZKER, RAQUEL JACONI DE CARLI, \\ TAIS DENICOL, THAINA CIDREIRA, THAYNAN VIEIRA and FABRICIA PETRONILHO
}

Laboratory of Neurobiology of Inflammatory and Metabolic Processes, Graduate Program in Health Sciences, Health Sciences Unit, University of South Santa Catarina, 88704-900 Tubarão, SC, Brazil

Manuscript received on April 24, 2019; accepted for publication on August 2, 2019

\begin{abstract}
How to cite: GIUSTINAAD, DANIELSKI LG, NOVOCHADLO MM, GOLDIM MPS, JOAQUIM L, METZKER KLL, CARLI RJ, DENICOL T, CIDREIRA T, VIEIRA T AND PETRONILHO F. 2019. Vitamin B6 reduces oxidative stress in lungs and liver in experimental sepsis. An Acad Bras Cienc 91: e20190434. DOI 10.1590/0001-3765201920190434.
\end{abstract}

\begin{abstract}
Sepsis is a life-threatening organ dysfunction induced by a disrupted host response to infecting pathogens. Inflammation and oxidative stress are intrinsically related to sepsis progression and organ failure. Vitamin B6 is an important cellular cofactor for metabolic processes and has anti-inflammatory and antioxidant properties. We aimed at evaluating the effect of vit B6 on inflammation and oxidative stress markers in the liver and lung of rats subjected to a relevant animal model of polymicrobial sepsis. Adult male Wistar rats were submitted to cecal ligation and perforation model and immediately after sepsis induction, vit B6 was administered as a single dose (600 mg/kg, subcutaneous). Twenty-four hours later, the lung and liver were harvest for neutrophil infiltration, oxidative markers to lipids and protein and antioxidant activity of endogenous enzyme. Vitamin B6 diminished neutrophil infiltration in both organs, oxidative markers in the liver and restored catalase activity levels in the lung of septic animals. Vitamin B6 exerts anti-inflammatory and antioxidant effects in peripheral organs after polymicrobial sepsis.
\end{abstract}

Key words: sepsis, vitamin B6, oxidative stress, antioxidant.

\section{INTRODUCTION}

Sepsis is a life-threatening organ dysfunction induced by a dysregulated host response to infectious stimuli (Singer et al. 2016). The pathologic hallmark of sepsis relies on the failure to maintain a satisfactory balance between excessive and inadequate inflammatory response, leading to a massive generation of reactive oxygen species (ROS) and nitrogen species (RNS) (Andrades et al. 2009). Reactive species promote several

Correspondence to: Fabricia Petronilho

E-mail: fabricia.petronilho@unisul.br

ORCid: https://orcid.org/0000-0003-3240-2808 proinflammatory effects, such as neutrophil recruitment (Hotchkiss and Karl 2003), and favor the occurrence of oxidative damage due to an imbalanced activity of endogenous enzymes, including catalase (CAT) (Andrades et al. 2005). As oxidative stress plays an important role in the development of sepsis-induced organ dysfunction, the application of antioxidant compounds has been considered a potential and promisor treatment (Ritter et al. 2004).

Vitamin B6 (vit B6) is a water-soluble vitamin easily found as pyridoxal, pyridoxine and pyridoxamine forms in animal and vegetal foods (Salam et al. 2015). After digestion and absorption, 
the liver converts vit B6 to the biologically active form, pyridoxal 5'-phosphate (PLP). PLP is then bound by albumin and corresponds to approximately $60 \%$ of circulating vit B6 (Wang and Kuo 2007). Importantly, PLP serves as a cofactor for innumerous reactions related to macronutrients metabolism and immune response (Mooney et al. 2009).

Evidences point an inverse relationship between blood levels of vit B6 and inflammation, as subjects with decreased levels of vit B6 display higher concentrations of inflammatory markers, possibly because PLP is drawn out into sites of active inflammation (Ueland et al. 2017). In addition, vit B6 acts in the antioxidant system and inhibits lipid peroxidation (Choi and Cho 2009). In this sense, we aimed to evaluate the possible antioxidative and anti-inflammatory effects of an acute treatment with vit B6 in the liver and lung of rats submitted to an animal model of polymicrobial sepsis.

\section{MATERIALS AND METHODS}

\section{ANIMALS}

Adult male Wistar rats (weighing 250 - $350 \mathrm{~g}$ ) from the Universidade do Vale do Itajaí and maintained at the Universidade do Sul de Santa Catarina were used. The animals were housed five per cage under controlled conditions of temperature $\left(22 \pm 1^{\circ} \mathrm{C}\right)$, relatively humidity (45-55\%) and day/light cycle (12:12 h, light on at 06 a.m.). Rat chow (standard diet for laboratory animals - NUVILAB CR-1 ${ }^{\circledR}$, Brazil) and tap water were available ad libitum. All procedures performed were made in accordance with the ethical standards of the Animal Research Ethic Committee of the Universidade do Sul de Santa Catarina (protocol \#15.0 12.4.03.IV). The Guide for the Care and Use of Laboratory Animals (The National Academies Press, $8{ }^{\text {th }}$ Edition, 2011) was followed in all experiments. All efforts were made to minimize the number of animals used and their suffering.

\section{SEPSIS INDUCTION - CLP MODEL}

Rats were subjected to CLP as previously described with minor modifications (Danielski et al. 2017) to induce mid-grade sepsis (Rittirsch et al. 2009). To minimize variability between different experiments, the CLP procedure was always performed by the same investigators.

\section{TREATMENTS AND SAMPLES OBTENTION}

Vitamin B6 (Fagron, São Paulo, Brazil) was dissolved in saline immediately before use and protected from the light during the experiments. Immediately after surgery, rats received $600 \mathrm{mg} /$ $\mathrm{Kg}$ s.c. of vitamin $\mathrm{B} 6$ or the same volume of vehicle (Barichello et al. 2014). Four groups ( $\mathrm{n}=$ 10) were randomly divided into: (1) sham + saline; (2) sham+B6, (3) CLP+saline, and (4) CLP+B6. Twenty-four hours after the surgery procedure (CLP or sham), animals were subjected to a thiopental overdose $(0.5 \mathrm{~g} / \mathrm{kg}$, i.p. $)$ followed by decapitation as a secondary euthanasia method. The lung and the liver were quickly isolated by hand dissection and the samples were stored at $-80^{\circ} \mathrm{C}$ for subsequent analysis.

\section{BIOCHEMICAL ANALYSIS}

Myeloperoxidase activity: Neutrophil infiltration in tissues was evaluated by the measurement of myeloperoxidase (MPO) activity (De Young et al. 1989). The activity was measured spectrophotometrically as the change in absorbance at $650 \mathrm{~nm}$ at $37^{\circ} \mathrm{C}$. Data was expressed as $\mathrm{mU}$ per milligram of protein.

Thiobarbituric Acid Reactive Species formation: Lipid peroxidation was evaluated by the formation of thiobarbituric acid reactive substances (TBARS). The optical density of each solution was measured in a spectrophotometer at $535 \mathrm{~nm}$. The 
results were expressed as nmol of malondialdehyde (MDA) equivalents per milligram of protein (Draper and Hadley 1990).

Protein carbonyl formation: Protein oxidation was evaluated by the determination of carbonyl groups based on the reaction with dinitrophenylhidrazine, as previously described (Levine et al. 1990). The absorbance was read at $370 \mathrm{~nm}$ and carbonyl protein levels were expressed as nmol per milligram of protein.

Catalase activity: Catalase (CAT EC 1.11.1.6) activity was measured according to its ability to decompose $\mathrm{H}_{2} \mathrm{O}_{2}$ into water and oxygen (Aebi 1984). The absorbance was measured in a spectrophotometer at $240 \mathrm{~nm}$ in 0,30 and 60 seconds after the reaction started. CAT specific activity was represented as $\mathrm{mU}$ per milligram of protein.

Protein determination: All results were normalized with proteins levels measured by the Lowry method using bovine serum albumin as a standard. The absorbance was read in $700 \mathrm{~nm}$ and the results were expressed as milligram of protein (Lowry et al. 1951).

\section{DATA ANALYSIS}

Data was analyzed using the Statistical Package for the Social Sciences software (SPSS, Chicago, IL, USA). Results were expressed as mean \pm S.D., and each value reflects 7 animals per group. Differences among experimental groups were determined by one-way analysis of variance (ANOVA), followed by post-hoc Tukey test. In all comparisons, statistical significance was set at $p<0.05$.

\section{RESULTS}

Inflammation and antioxidant activity: We verified a significant increase in MPO activity in the lung (Fig. 1a) and the liver (Fig. 1b) of CLP+saline animals $(p<0.05$, vs. sham + saline $)$, while the rats subjected to sepsis and treated with vit B6 presented a significative reduction in the levels of MPO in both organs ( $p<0.05$ vs. CLP + saline). With regards to CAT activity, the administration of vit B6 significantly avoided sepsis-induced reduction in CAT activity in the lungs (Fig. 1c; $p$ $<0.05, \mathrm{CLP}+\mathrm{B} 6$ vs. CLP+saline), while it did not exert significative effect in the liver (Fig. 1d).

Oxidative damage: Sepsis enhanced MDA levels in the lung (Fig. 2a) and liver (Fig. 2b) at $24 \mathrm{~h}$ after CLP surgery ( $p<0.05$ vs. sham + saline). A single administration of vit B6 immediately after sepsis induction significantly prevented an increase in TBARS formation in the liver (Fig. 2b), but not in the lung, of CLP+B6 rats ( $p<0.05$ vs. $\mathrm{CLP}+$ saline). Septic rats showed a higher oxidative damage to carbonyl groups in the lung (Fig. 2c) and liver (Fig. 2d), compared to sham+saline animals. Treatment with vitamin B6 significantly prevented this alteration only in the liver $(p<0.05$ vs. CLP+saline).

\section{DISCUSSION}

In this study, we demonstrate the acute protective effects of vit B6 on peripheral organs of rats subjected to a well-established model of polymicrobial sepsis. A single dose of vit B6 administered immediately after surgery improved an inflammatory marker and oxidative parameters in the liver and lung.

Neutrophils are the first line of defense crucial during the early stages of sepsis as they release important inflammatory mediators, engulf invading pathogens, and contribute directly to antimicrobial killing via expression of several antimicrobial peptides, proteases, and oxidants (Reddy and Standiford 2010). Here we demonstrate that sepsis increased the levels of MPO, thus indicating the occurrence of an inflammatory response at 24 hours after CLP surgery. On the contrary, septic rats treated with vit $\mathrm{B} 6$ showed diminished activity of MPO, meaning that vit B6 decreased the acute neutrophil-induced inflammatory response in these 

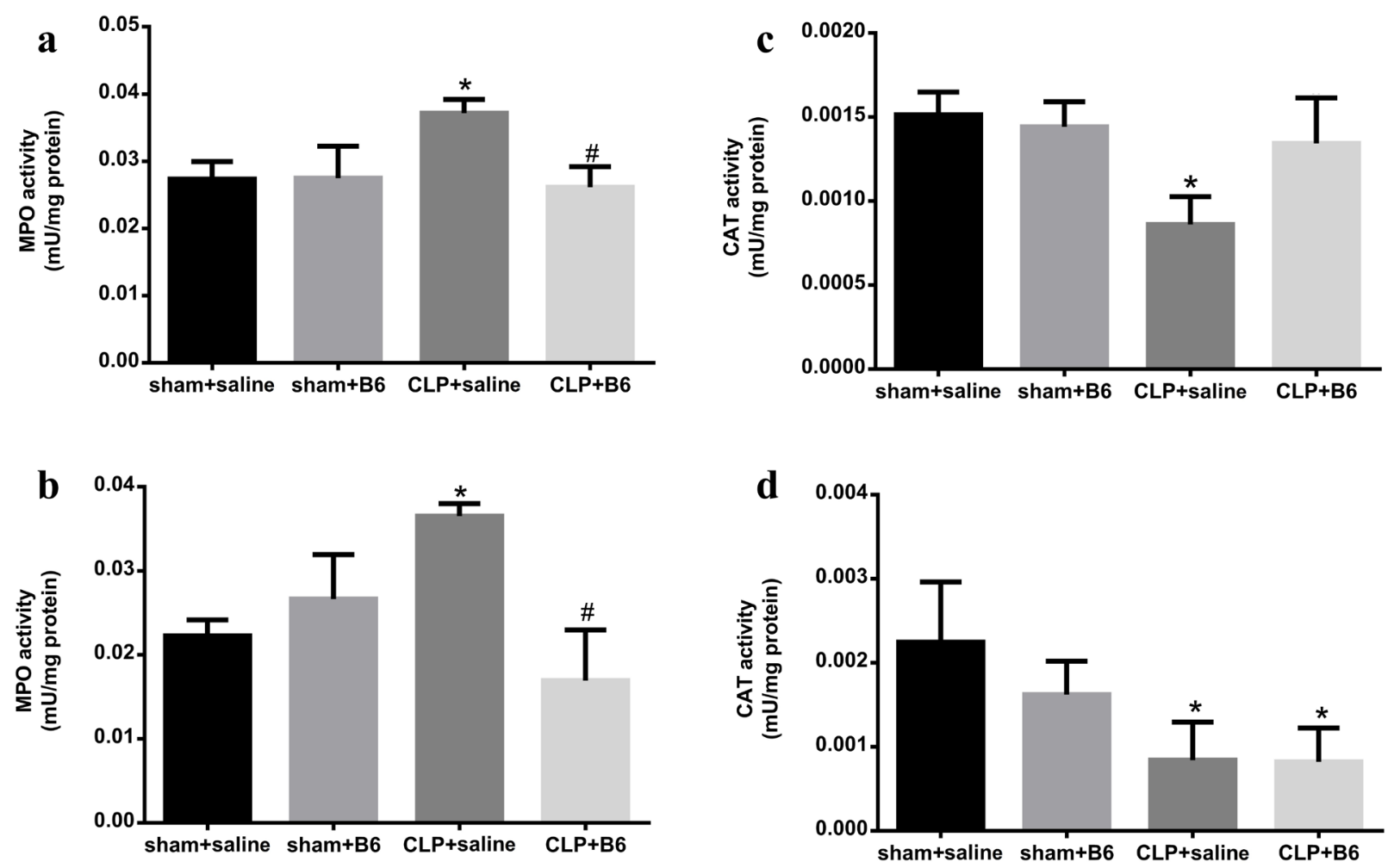

Figure 1 - Myeloperoxidase activity in the lung (a) and liver (b) and catalase activity in the lung (c) and liver (d) of rats subjected to polymicrobial sepsis and treated with vitamin B6 $(600 \mathrm{mg} / \mathrm{Kg})$. Data is expressed as mean \pm standard deviation, analyzed by oneway ANOVA with Tukey post-hoc test. ${ }^{*} p<0.05$ compared to sham + saline group and ${ }^{*} p<0.05$ compared to CLP+saline group.

animals. Similar results were found in previous studies in which we demonstrate the role of vit B6 in preventing the increase of MPO activity in different brain structures of septic rats (Danielski et al. 2017) and also the action of alpha-lipoic acid - an antioxidant compound - on peripheral organs after sepsis induction (Petronilho et al. 2015).

Furthermore, the inflammatory infiltrate is also responsible for producing a considerable amount of ROS and RNS to eliminate pathogens and apoptotic cells (Pfeilschifter et al. 2003). Both types of reactive species can contribute to lipid peroxidation, since membrane lipids and lipoproteins are particularly susceptible to oxidative damages due to their polyunsaturated fatty acidsenriched composition. The end products of lipid peroxidation, such as malondialdehyde, can lead to protein damage by reactions with several amino groups (Piechota-Polanczyk and Fichna 2014).
In our research, we evidence that sepsis incited oxidative damage to lipids and proteins in the liver and the lung at 24 hours after CLP surgery. Previous evidence suggests that the magnitude of lipid peroxidation, but not the time when it occurs, is influenced by sepsis severity; on the contrary, both magnitude and time of protein oxidation are determined by sepsis severity (Andrades et al. 2005).

Furthermore, the administration of a single dose of vit B6 immediately after surgery significantly reduced oxidative damage in the liver of septic rats. Antioxidants compounds may regulate ROS-related enzymes either by inhibiting the activities and/or expressions of free radical generating enzymes, or by enhancing the activities and expressions of endogenous antioxidant enzymes (Lü et al. 2010). Vitamin B6 displays significant antioxidant functions mainly by scavenging superoxide 

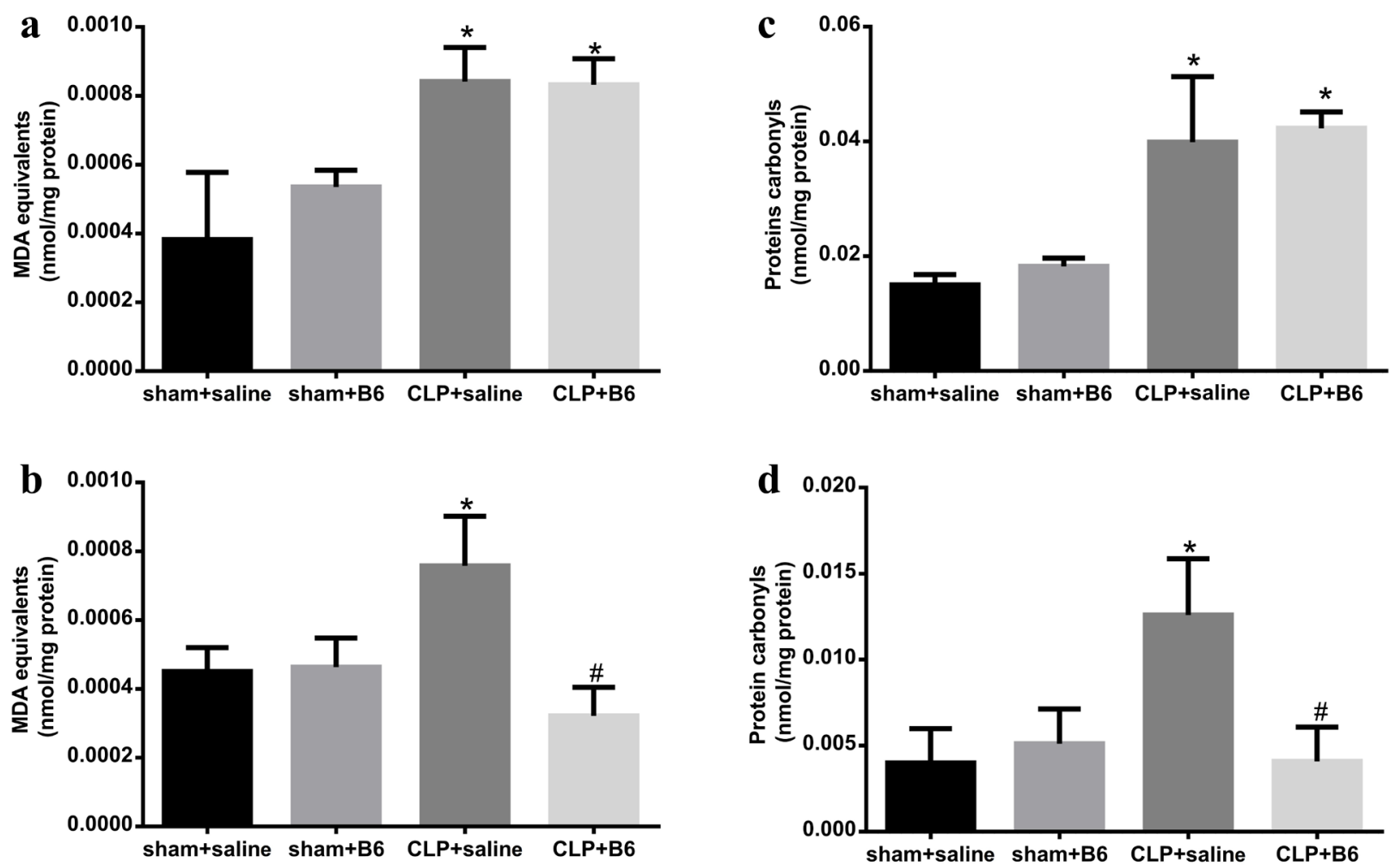

Figure 2 - Lipid peroxidation in the lung (a) and liver (b) and protein carbonylation in the lung (c) and liver (d) of rats subjected to polymicrobial sepsis and treated with vitamin B6 $(600 \mathrm{mg} / \mathrm{Kg})$. Data is expressed as mean \pm standard deviation, analyzed by oneway ANOVA with Tukey post-hoc test. ${ }^{*} p<0.05$ compared to sham + saline group and ${ }^{*} p<0.05$ compared to CLP + saline group.

radicals (Mahfouz et al. 2009). In the present study, we measured the activity of CAT, and vit B6 was effective in preventing the decrease of CAT activity in the lung. Importantly, pyridoxine has an essential role for the synthesis of glutathione peroxidase (Dalto and Matte 2017), thus it is possible that vit B6 treatment exerted a positive effect on the glutathione peroxidase (GPx) availability and contributed to diminish the oxidative damages. However, as we did not measure GPx activity, this possible influence is limited to speculation.

The administration of vit B6 immediately after sepsis induction in rats reduced neutrophil infiltrate in the liver and lung, diminished the oxidative damage to lipids and protein in the liver, and increased CAT activity in the lung at 24 hours after surgery. In conclusion, vitamin B6 exerts positive effects in modulating neutrophil infiltrate and oxidative stress in peripheral organs of rats subjected to a model of polymicrobial sepsis.

\section{ACKNOWLEDGMENTS}

This research was supported by the Conselho Nacional de Desenvolvimento Científico e Tecnológico (CNPq); and the Coordenação de Aperfeiçoamento de Pessoal de Nível Superior (CAPES) (FP). FP and TB are CNPq Research Fellows. The funding sources were not involved in the conduction of the research, preparation of the article nor in the decision to submit the article for publication. The authors declare that they have no conflict of interest.

\section{AUTHOR CONTRIBUTIONS}

FP supervised the research, designed experiments, analyzed data and co-wrote the paper. ADG 
performed animal experiments and co-wrote the paper. LGD, MMN, LJ, KLLM and RJC performed animal experiments and collected samples. TD, TC and TV performed biochemical analyses. MPSG analyzed data and co-wrote the paper.

\section{REFERENCES}

AEBI H. 1984. Catalase in Vitro. Methods Enzymol 105: 121126.

ANDRADES M E, RITTER C AND DAL-PIZZOL F. 2009.

The Role of Free Radicals in Sepsis Development. Front Biosc 1(1): 277-287.

ANDRADES M, RITTER C, MOREIRA JCF AND DALPIZZOL F. 2005. Oxidative Parameters Differences during Non-Lethal and Lethal Sepsis Development. J Surg Res 125(1): 68-72.

BARICHELLO T, GENEROSO JS, SIMÕES LR, CERETTA RA, DOMINGUINI D, FERRARI P, GUBERT C, JORNADA LK, BUDNI J, KAPCZINSKI F AND QUEVEDO J. 2014. Vitamin B6 Prevents Cognitive Impairment in Experimental Pneumococcal Meningitis. Exp Biol Med 239(10): 1360-1365.

CHOI E-Y AND CHO Y-O. 2009. Effect of Vitamin B(6) Deficiency on Antioxidative Status in Rats with ExerciseInduced Oxidative Stress. Nut Res Practice 3(3): 208-211.

DALTO D B AND MATTE J-J. 2017. Pyridoxine (Vitamin $\mathrm{B}(6)$ and the Glutathione Peroxidase System; a Link between One-Carbon Metabolism and Antioxidation. Nutrients 9(3).

DANIELSKI LG ET AL. 2017. Vitamin B6 Reduces Neurochemical and Long-Term Cognitive Alterations after Polymicrobial Sepsis: Involvement of the Kynurenine Pathway Modulation. Mol Neurobiol 55(6): 5255-5268.

DRAPER HH AND HADLEY M. 1990. Malondialdehyde Determination as Index of Lipid Peroxidation. Methods Enzymol 186: 421-431.

HOTCHKISS RS AND KARL IE. 2003. The Pathophysiology and Treatment of Sepsis. The N Engl J Med 348(2): 138150.

LEVINE RL, GARLAND D, OLIVER CN, AMICI A, CLIMENT I, LENZ AG, AHN BW, SHALTIEL S AND STADTMAN ER. 1990. Determination of Carbonyl Content in Oxidatively Modified Proteins. Methods in Enzymol 186: 464-478.

LOWRY OH, ROSEBROUGH NJ, FARR AL AND RANDALL RJ. 1951. Protein Measurement with the Folin Phenol Reagent. J Biol Chem 193(1): 265-275.

LÜ J-M, LIN PH, YAO Q AND CHEN C. 2010. Chemical and Molecular Mechanisms of Antioxidants: Experimental Approaches and Model Systems. J Cel Mol Med 14(4): 840-860.
MAHFOUZ MM, ZHOU SQ AND KUMMEROW FA. 2009. Vitamin B6 Compounds Are Capable of Reducing the Superoxide Radical and Lipid Peroxide Levels Induced by $\mathrm{H} 2 \mathrm{O} 2$ in Vascular Endothelial Cells in Culture. Int J Vitam Nutr Res 79 (4): 218-229.

MOONEY S, LEUENDORF J-E, HENDRICKSON C AND HELLMANN H. 2009. Vitamin B6: A Long Known Compound of Surprising Complexity. Molecules 14(1): 329-351.

PETRONILHO F, FLORENTINO D, DANIELSKI LG, VIEIRA LC, MARTINS MM, VIEIRA A, BONFANTE S, GOLDIM MP AND VUOLO F. 2015. Alpha-Lipoic Acid Attenuates Oxidative Damage in Organs after Sepsis. Inflammation 39(1): 357-365.

PFEILSCHIFTER J, EBERHARDT W AND HUWILER A. 2003. Nitric Oxide and Mechanisms of Redox Signaling. J Am Soc Nephrol 14(8 Suppl 3): S237-240.

PIECHOTA-POLANCZYK A AND FICHNA J. 2014. Review Article: The Role of Oxidative Stress in Pathogenesis and Treatment of Inflammatory Bowel Diseases. NaunynSchmiedeberg's Arch Pharmacol 387(7): 605-620.

REDDY RC AND STANDIFORD TJ. 2010. Effects of Sepsis on Neutrophil Chemotaxis. Curr Opin Hematol 17(1): 1824.

RITTER C, ANDRADES ME, REINKE A, MENNABARRETO S, MOREIRA JCF AND DAL-PIZZOL F. 2004. Treatment with N-Acetylcysteine plus Deferoxamine Protects Rats against Oxidative Stress and Improves Survival in Sepsis. Crit Care Med 32(2): 342-349.

RITTIRSCH D, HUBER-LANG MS, FLIERL M AND WARD P. 2009. Immunodesign of Experimental Sepsis by Cecal Ligation and Puncture. Nat Protoc 4(1): 31-36.

SALAM RA, ZUBERI F AND BHUTTA ZA. 2015. Pyridoxine (Vitamin B6) Supplementation during Pregnancy or Labour for Maternal and Neonatal Outcomes. Cochrane Database Syst Rev 6: CD000179.

SINGER M, DEUTSCHMAN MS, SEYMOUR CW, SHANKAR-HARI M, ANNANE D, BAUER M, BELLOMO R AND BERNARD GR. 2016. The Third International Consensus Definitions for Sepsis and Septic Shock (Sepsis-3). JAMA 315(8): 801-810.

UELAND PM, MCCANN A, MIDTTUN O AND ULVIK A. 2017. Inflammation, Vitamin B6 and Related Pathways. Mol Aspects Med 53(1): 10-27.

WANG H-S AND KUO M-F. 2007. Vitamin B6 Related Epilepsy during Childhood. Chang Gung Med J 30(5): 396-401.

YOUNG LM, KHEIFETS JB, BALLARON SJ AND YOUNG JM. 1989. Edema and Cell Infiltration in the Phorbol EsterTreated Mouse Ear Are Temporally Separate and Can Be Differentially Modulated by Pharmacologic Agents. Agents Actions 26(3-4): 335-341. 